\title{
What Paint Can Tell Us: A Fractal Analysis of Neurological Changes in Seven Artists
}

\author{
Alex Forsythe \\ University of Liverpool
}

\author{
Tamsin Williams \\ Tees, Esk, and Wear Valleys NHS Trust, Vale of York, \\ United Kingdom
}

\author{
Ronan G. Reilly \\ Maynooth University
}

\begin{abstract}
Objective: The notion that artistic capability increases with dementia is both novel and largely unsupported by available literature. Recent research has suggested an emergence of artistic capabilities to be a by-product of involuntary behaviour seen with dementia, as opposed to a progression in original thinking (de Souza, et al., 2010). A far more complementary explanation comes from Hannemann (2006), who suggests that art offers an outlet for dementia patients to refine and sharpen their cognitive abilities. As dementia severely impedes linguistic skills, non-verbal therapeutic methods such as painting can permit dementia patients to express themselves in a way not possible verbally. Fractal analysis has been used to determine the authenticity of major works of art. Taylor et al., (1999) found that through a fractal analysis of Jackson Pollock's paintings it was possible to distinguish authentic works from a large collection of fakes, demonstrating that when artists paint they instill within their work their own pattern of unique fractal behaviour. Can age-indexed variations in the fractal dimension of the works of artists anticipate specific cognitive deteriorations? Method: To answer this question we analysed age-related variations in the fractal dimension of a large corpus of digital images $(n=2092)$ of work created by seven notable artists who experienced both normal ageing and neurodegenerative disorders. Results: The results of our analysis showed that patterns of change in the fractal dimension of the paintings differentiated artists who suffered neurological deterioration from those of normal aging controls. Conclusions: These findings are of importance for two reasons. Our work adds to studies that demonstrate that fractal analysis has the potential to determine the provenance of paintings. Secondly, our work suggests that may be possible to identify a-typical changes in the structure of an artist's work; changes that may be early indicators of the onset of neurological deterioration.
\end{abstract}

Keywords: Alzheimer's disease, Parkinson's disease, fractal dimension artists

The study of linguistic changes as an early indicator of cognitive deterioration has an established history. The classic Nun Study (Snowdon et al., 1996) examined the linguistic capabilities of 93 nuns from a convent in Wisconsin (ages at time of study ranged from 75 to 95 years). Lexical analysis determined that low scores in idea density and grammatical capability in the autobiographical works written in early life strongly correlated with low scores for cognitive ability in later life. Neuropathological examinations of 14 of the nuns presented post mortem diagnosis of Alzheimer's disease (AD), a condition not reported in sisters who scored highly for idea density in early life. Similarly, Butterwort reports that the speeches of Ronald Reagan showed language deterioration akin to

Alex Forsythe, Department of Psychology, University of Liverpool; Tamsin Williams, Tees, Esk, and Wear Valleys NHS Trust, Vale of York, United Kingdom; Ronan G. Reilly, Department of Computer Science, Maynooth University.

Correspondence concerning this article should be addressed to Alex Forsythe, School of Psychology, Room 2.78a, Eleanor Rathbone Building, University of Liverpool, Liverpool L69 7ZA, United Kingdom. E-mail: A.Forsythe@liverpool.ac.uk the onset of AD (Butterworth, 1984, reported in Forbes-McKay \& Venneri, 2005). Reagan displayed significant decline within five linguistic categories. For example, he did not display any confusion errors in 1980, though they were present in the 1984 debate. Butterworth conclusions were that Reagan's linguistic decline since 1980 was an indicator of the initial signs of AD, a conclusion confirmed 10 years later, when Reagan received his official diagnosis of AD. Computational linguistic analysis has demonstrated that is it possible to detect early signs of $\mathrm{AD}$ in the late works of the novelist and philosopher Iris Murdoch (Leslie, 2004). In contrast to other Murdoch novels, her work was shown to have fewer numbers of unique word types relative to the word count (Garrard, Maloney, Hodges, \& Patterson, 2005).

Artists manifest visual, motor, auditory and cognitive neuropsychological deficits in strikingly eloquent ways (Chatterjee, 2004). Artists often remain motivated, productive and expressive and, despite deficits in visual processing skills and motor capabilities, their personal style, depth, balance and quality of stroke are frequently well preserved (Van Buren, Bromberger, Potts, Miller, \& Chatterjee, 2013). Mell, Howard, and Miller (2003) describe the case study of a painter with frontotemporal dementia. Though her ability to organize class lessons or grade homework declined, her 
paintings became freer, more intricate and original. The painter Danae Chambers, diagnosed with AD with anterior lobe damage, continued to paint with enduring creativity for 10 years before the quality of her art began to suffer (Fornazzari, 2005). With a Mini-Mental State Examination score of 8, Chambers was able to create form and precision in her paintings, and retained the ability to correct errors. Eventually Chambers' attention to detail deteriorated, her figures lacked proportion and she applied heavy dark colors to her work. Fornazzari reasons that, while Chambers was experiencing a decline in attention, working memory, and episodic memory, visuoconstructive capabilities were probably preserved.

Espinel (1996) reports similar trends in the work of Willem De Kooning, who continued to paint even after he developed AD. It is widely agreed among art historians that, although De Kooning's work was simpler in nature and restricted to primary shades, his post $\mathrm{AD}$ work reflected a new coherent, intense style, demonstrating the artist's ability to discern visually pleasing abstract forms, shapes and colors (see, e.g., Rider Untitled VII by Willem de Kooning, 1985, The Museum of Modern Art, New York).

In their review of 14 case studies Gretton and ffytche (2014), identified some broad generalizations in artistic change across the different dementias. AD presents prominent changes in the spatial aspects, color and contrast. For example, the artist Lester Potts was a saw miller until diagnosed with AD. Potts went on to become an acclaimed watercolor artist, and we can see the progression of the disease through his works (Figure $1 \mathrm{a}-\mathrm{c}$ ). Potts early works are full of detail, color, and contrast (Figure 1a). As the disease progressed Potts focused less on color, rather he would draw shapes repeatedly (Figure 1b). Toward the end of his life we see him loose interest, preferring to draw simple gray images with repeating patterns that capture aspects of his previous life as a saw miller (Figure 1c).

A similar pattern can be observed in the work of the magazine illustrator Carolus Horn (1921-1992). Horn annually visited Venice to paint. Figure 2a and b ("Bridge of Sighs") shows the changes in his paintings as the disease progressed. Fine detail became replaced with heavier lines and color primary colors became preferred, with images becoming progressively two-dimensional and toward the end (Figure 2c) with realism lost and a single-color, childlike image created (Bogousslavsky \& Boller, 2005; Maurer \& Prvulovic, 2005).

Lewy body dementia (LBD) is characterized by a different pattern of artistic change with works containing simple, bizarre content. For example, as William Utermohlen's (1933-2007) AD advanced, his paintings are described as becoming oversimplified with a distinct lack of a relationship between proportion and perspective (see Figure 3). These simple, abstract and often unusual creations have been compared to the Alison in Wonderland illustrator, Mervyn Peak (Figure 4 a, b). Peaks' condition is ascribed by different writers to AD, Parkinson's disease (PD), or postencephalitic Parkinsonism, however Sahlas (2003), following a detailed review, produced substantial evidence in support of a probable diagnosis of LBD.

Some systematic changes in artistic style are also reported for those suffering from PD, particularly reduced precision and a stronger engagement with kinesthetic movements. For example, Johanne Vermette felt that her PD increased her creativity, but that her work became less precise (Pinker, 2002). Chatterjee, Hamilton, and Amorapanth (2006) described a graphic designer with im- paired distal movements becoming fluid and more controlled when he applied winding proximal movements of larger amplitude. Walker, Warwick, and Cercy (2006) reported on the painting skills of an artist with PD who produced excessive amounts of pastels under dopamine agonists, which had a strong sense of color and kinaesthesia. The relationship between dopamine drugs and increased artistic output has also been reported in art-naïve PD patients (Inzelberg, 2013); however, it is important to differentiate between increased artistic output and true creativity. Such drugs provoke new behavioral responses such as social inhibition, but artistic output is not the same as creativity. Creativity requires emotional expression, technical ability and an appreciation of evocative impact, planning, fluency, and mental flexibility (de Souza et al., 2014).

Gretton and ffytche (2014) argued that there has been a significant underrepresentation of art-dementia studies. There are a number of potential biases in the literature, particularly around the measure of changes in an artist's work (Van Buren et al., 2013). Detailed biographical information is often preferred because attributing changes in an artist's work as an indicator of the onset of a disease is problematic because the symptoms may predate clinical diagnosis by several years. That being said, studies that capture deficits in higher functions and faculties are particularly useful in understanding deficits distributed across brain regions. Focusing on artists spotlights the ways in

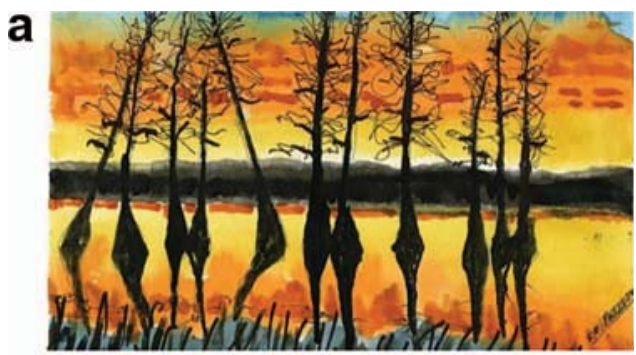

b

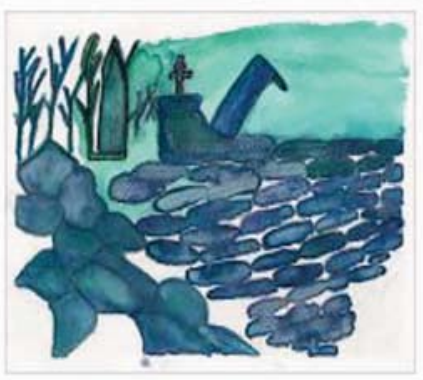

C

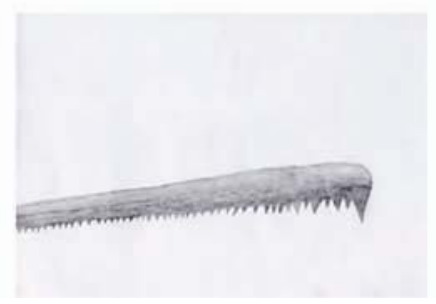

Figure 1. Lester Potts. (a) "Sunset." (b) "Blue Green Collage." (c) "The Cross Cut Saw." All reprinted with permission from Daniel Potts. See the online article for the color version of this figure. 


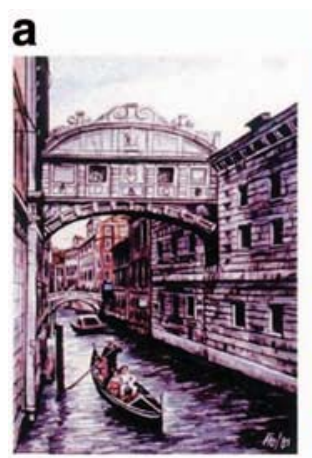

b

C

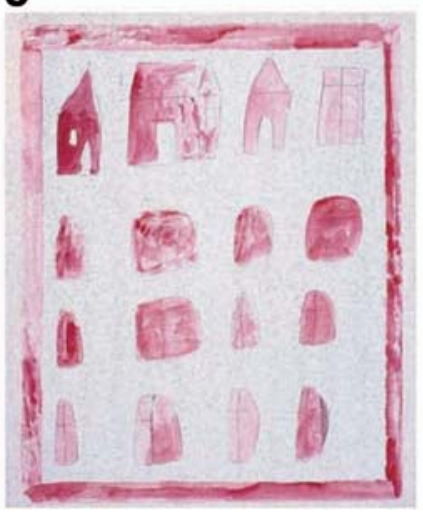

Figure 2. Carolus Horn. (a, 1981; b, 1987) "Final painting of the Bridge of Sighs." (c) "Carolus Horn: Final Stages." All from "Paintings of an Artist With Alzheimer's Disease: Visuoconstructural Deficits During Dementia," by K. Maurer and D. Prvulovic, 2004, Journal of Neural Transmission, 111, pp. 235-245. Copyright 2004 by Springer. See the online article for the color version of this figure.

which specific cognitive deficits might enhance or diminish a given aspect of their work. The authors went on to demonstrate that certain neurological conditions do in fact present a pattern of artistic change, which could function as a useful classificatory scheme for neuro-

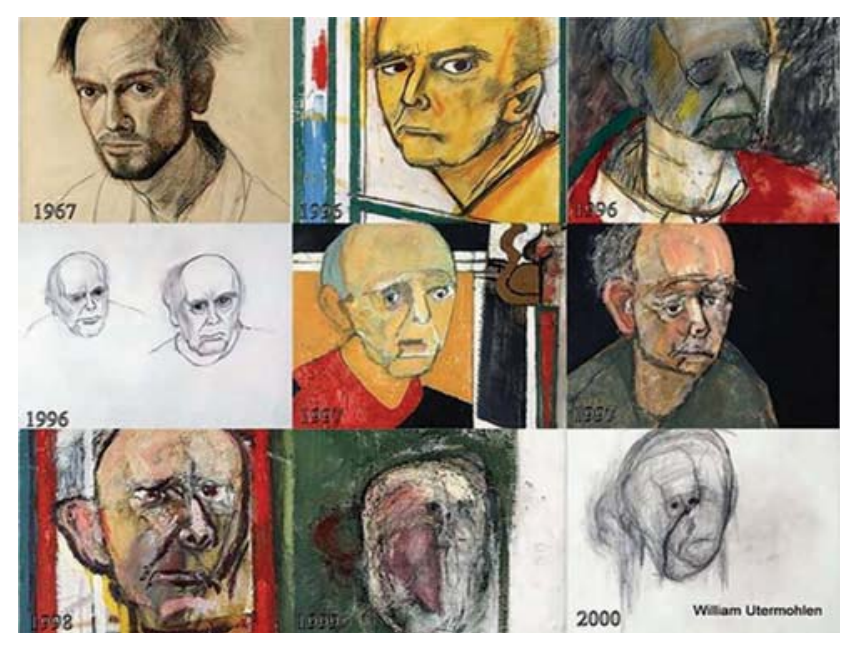

Figure 3. William Utermohlen. "Self Portraits." Reprinted with permission of Patricia Utermohlen. See the online article for the color version of this figure. a

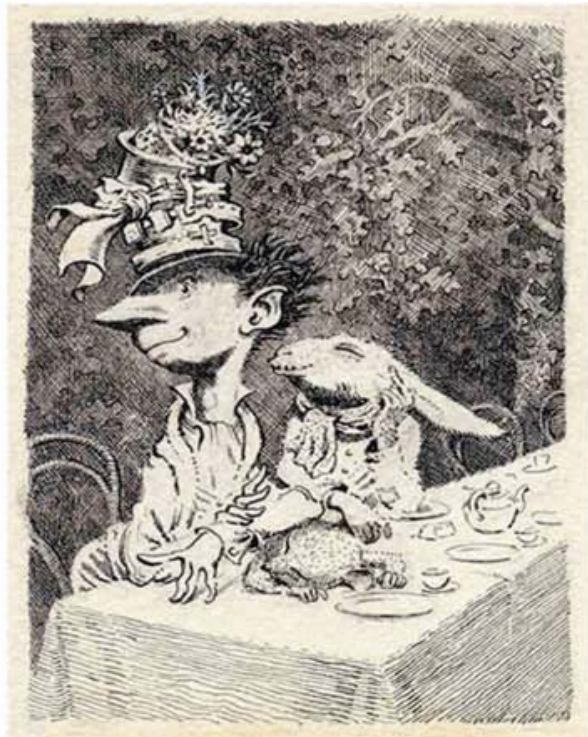

b

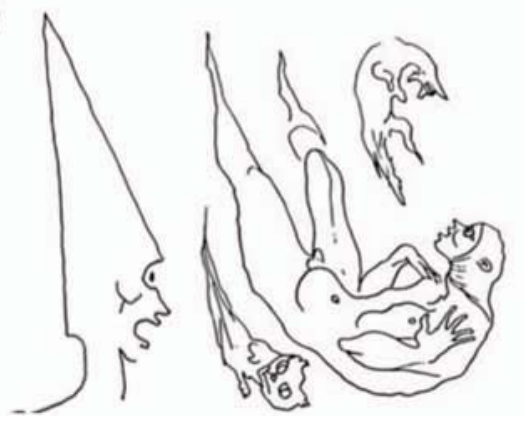

Figure 4. Mervyn Peak. (a) "The Hatter and the March Hare." Copyright the British Library Board, Add MS 88931/7/1/5, Folio 9. (b) "With Dunce Cap." Reprinted by permission of Peters Fraser and Dunlop (www. petersfraserdunlop.com) on behalf of the Estate of Mervyn Peake. See the online article for the color version of this figure.

degenerative decline. The authors argued that more longitudinal designs are needed, and here, we attempt to answer this recommendation by reporting on a series of case study analyses of the works of painters who, in the later stages of life, were diagnosed with a neurodegenerative disorder. Such historical analyses do not provide a microscope on the artistic patterns of different types of dementias, in the style of Gretton and ffytche, because the specifics of the artists' disorders examined here, are unconfirmed by autopsy. However, a review of the dementia literature would suggest that two of the artist, James Brooks and Willem DeKooning, were possibly suffering from LBD. This is a small-sample study covering two different neuropsychological conditions, $\mathrm{PD}$ and $\mathrm{AD}$, the results of which are contrasted with artists who aged naturally.

\section{Fractal Dimension as a Predictor of Neurodegeneration}

Chaterjee et al. (2010) identified the lack of quantitative measures of art as a critical obstacle to the reliable measurement of 
change in the work of artists with cognitive impairments. The authors developed the Assessment of Art Attributes, a measurement system based on formal perceptual qualities (balance, color, depth, and complexity) and content representational attributes (emotion, abstraction, symbolism). While the Assessment of Art Attributes system's formalization of predetermined categories for measurement is an important step toward reliable artistic measurement, accurate assessment using this method requires at least some degree of artistic knowledge or training. Here, we apply fractal analysis as an objective measure of structural change in artworks over an artist's lifetime.

Fractals are mathematical characterizations of self-repeating patterns often described as the fingerprints of nature (Taylor, Micolich, \& Jonas, 1999). They can be created as art (Figure 5a) a

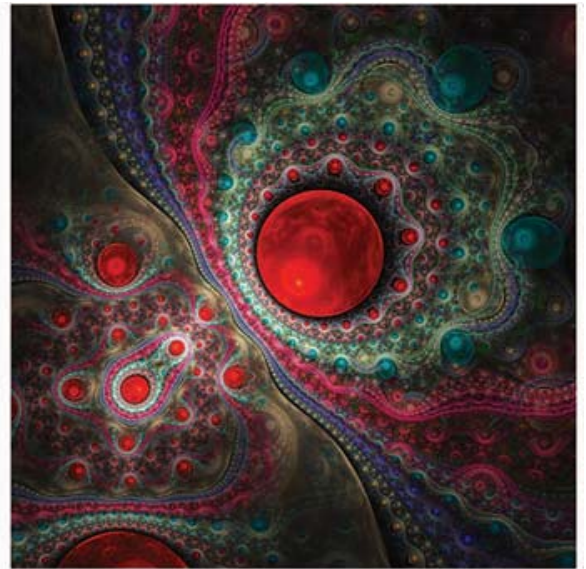

b

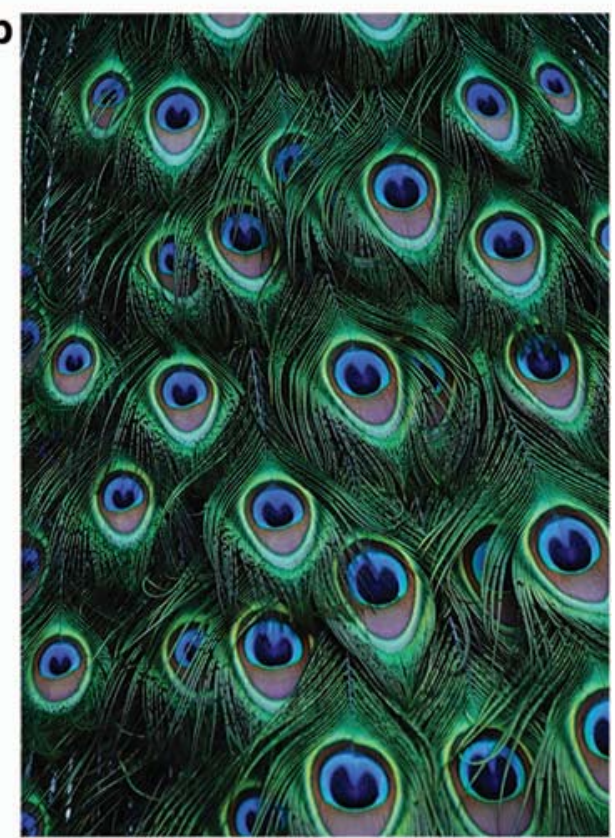

Figure 5. (a) "Mathematical Computer Generated Fractals." Copyright Dragonfly22 at Shutterstock. (b) "Natural Fractals. Peacock Feathers." Copyright fotohunter at Shutterstock. See the online article for the color version of this figure. or found in natural phenomena (Figure 5b) such as clouds, snowflakes, trees, rivers, and mountains (Gouyet, 1996; Mandelbrot \& Benoît, 1977). Viewing fractal patterns can elicit high alpha waves in areas associated with attention visual spatial processing (Hagerhall et al., 2008) and are associated with judgments of beauty in art, particularly when pictures are representative of something in the natural environment (Forsythe, Nadal, Sheehy, Cela-Conde, \& Sawey, 2011) and they have been found to be a valid measure of universal and individual preference (Street, Forsythe, Reilly, Taylor, \& Helmy, 2016).

Artists are known to operate within a particular range of fractal dimension (FD). Taylor et al. (2006) examined film footage of Jackson Pollock at work and concluded that Pollock was generating paintings with a high FD. That Pollock was able to fine-tune the structure of his paintings, gradually increasing their fractal content over a 10-year period. Pollock's fractal "signature" could be contrasted with recently discovered Pollock paintings, enabling a determination of authenticity. Here, we examine the usefulness of fractal analysis in detecting the onset of neurodegenerative deterioration. We analyzed 2,092 images from seven artists: Salvador Dalí and Norval Morrisseau, who were diagnosed with PD; James Brooks and Willem De Kooning, who developed AD; and Marc Chagall, Pablo Picasso, and Claude Monet, who showed no evidence of neurodegenerative diseases. Our working hypothesis is that heterogeneity in FD could indicate the onset and development of neurological changes.

\section{Methodology}

\section{Case Studies}

\section{Salvador Dalí (PD).}

Salvador Dalí, 1904-1989, is famed for his idiosyncratic and iconic contributions to the Surrealist movement. Dalî́s right hand trembled severely toward the end of his career. The causes of the tremor are disputed although it seems to be generally considered that the disease was typical idiopathic PD or drug-induced Parkinsonism. During the last 10 years of his life, Dalí also suffered from arteriosclerosis (a hardening of medium and large arteries) and by late 1980, Dalí's right hand was shaking severely. At this point he attended a PD specialist who determined that Dalí was more likely suffering from Parkinsonism caused by the cocktail of drugs being administered by his wife Gala. Gala died in June 1982, but Dalí continued to maintain his public image, ignoring the effects of the drugs and signing blank canvases for other artists to create a Dalí impersonation. The last work attributed to him was painted in 1983.

\section{Norval Morrisseau (PD, stroke and periodic alcoholism).}

Norval Morrisseau (1932-2007) took inspiration from Midewiwin scrolls, spiritual material that was passed orally from generation to generation in some Native American Tribes. He painted x-ray like images, probably drawn in the first instance in pencil, often depicting animal bones and skin at the same time. Many of the images were outlined with heavy black lines, and they were frequently filled with bright, sometimes neon coloring and were often painted with his fingertips. Morrisseau became ill during the 1990s, first with a stroke and then at the age of 65 he was diagnosed with PD. It is estimated that prior to diagnosis, Morrisseau may have created up to 10,000 paintings. Although his output decreased postdiagnosis, he continued to paint. Insofar as possible, we 
have worked closely with Norval Morrisseau Unlimited to include in our analyses only the authenticated works of Morrisseau.

\section{Willem De Kooning (AD).}

Art historians note a distinct difference between De Kooning's (1904-1997) late style and previous works (Garrels, 1997). De Kooning's earlier works had included abstract figures of women, multicolored prints, and canvases caked in oils (Espinel, 1996). Post-1970 saw De Kooning's attentions focused on creating ribbon like abstractions (Figure 1a, b). He lost interest in shape and form, becoming more interested in color. Paint was manipulated to appear hazy and faded at times, and he focused largely on using only primary colors. It has been suggested that this behavior was "symptomatic of neurological disorder" (Garrels, 1997). Sahlas (2003) goes further and draws parallels between the style expressed by De Kooning and patients with LBD. De Kooning received an official diagnosis of AD in 1989, though reports of observable symptoms were recorded in 1983.

\section{James Brooks (AD).}

James Brooks (1906-1992) was a renowned abstract expressionist painter, known primarily for pioneering abstract American art. Brooks enjoyed a diverse and rich artistic career, deriving influence from his peers, his own life experiences, various art classes, and art schools. As a consequence, his artistic style often changed, beginning with social realist art, developing into a cubist style before paving the way to more abstract expressionist pieces. Brooks was diagnosed with AD in 1985 and his production slowed to a virtual standstill. In 1992, he died in East Hampton, New York, at age 85. Again, we do not know the type of dementia Brooks presented with; however, we can see systematic changes in his artworks (Figure 6a, b) that fit with the LBD profile identified by Gretton and ffytche (2014).

\section{Marc Chagall (normal aging).}

From what we know of Chagall (1887-1985), he lived a relatively healthy and long life and died at the age of 98 of a heart attack. Often creating striking images using only two or three colors, Chagall manipulated the texture of his work through altering his media, favoring gouache, watercolor, or oil paints. In addition to paint, Chagall created some 24 lithographs, employing woodcuts and etching techniques in the creation of his prints.

\section{Claude Monet (normal aging).}

Monet (1840-1926) was the founder of French Impressionism, known for his consistent and prolific landscape painting. Monet rejected traditional landscapes painting, applying bright colors in dashes and swirls, often painting the same scene many times so that he could capture changes light or the passing seasons. Monet died at the age of 86 from lung cancer; he was known to have significant problems with his sight from 1911. In 1923, he underwent surgery for cataracts and he continued painting until his death (Gordon \& Forge, 1989). Monet worked with the paint laid down with omnidirectional brush strokes to the point that it is commonly impossible to tell how the surface was created. As described by Elkins (2000), truly directionless painting is immensely difficult, and artists have to work against their own anatomy to create this kind of effect. Figure 7 shows a subsection of a painting by Danielle O'Connor Akiyama demonstrating this particular technique.

\section{Pablo Picasso (normal aging).}

Picasso (1881-1973) is included in this study as an example of an artist who regularly changed his artistic style and died through the normal aging process. Early paintings were classical scenes of pho- a
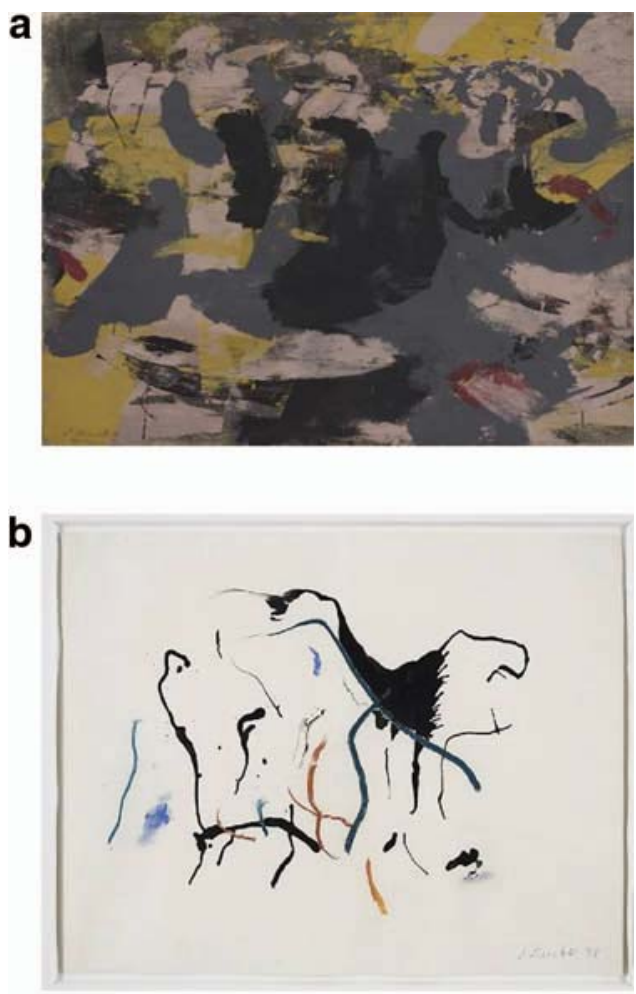

Figure 6. James Brooks. (a) "Qualm" (1950). Copyright 2016 James and Charlotte Brooks Foundation, Inc., Courtesy Metropolitan Museum of Art, New York. (b) "Untitled" (1978). Copyright 2016 James and Charlotte Brooks Foundation, Inc., Courtesy of Van Doren Waxter, New York. See the online article for the color version of this figure.

tographic quality, but by 1900, he favored a soft focus pastel effect, referred to as his "blue period." In 1904, "the rose period" saw Picasso soften his palette with depictions of graceful harlequins and acrobats. 1907 saw the creation of Picasso's first cubist piece. However, by 1909, having explored analytical cubism to its limits, Picasso shifted to collage cubism. In doing so, he varied his medium, utilizing cut out sections of material to form an image and adding lines to complete the piece. Picasso's 1917 "Portrait of Olga in Armchair" shows a shift in style once again, from cubism to neoclassicism. During the 1950s, Picasso began to alter his technique once again. Favoring simplified creations, he opted to leave parts of the canvas untouched. Picasso continued to work rapidly and frequently in his final years, which made for a large quantity of similar paintings. The paintings at this stage have a rough, sketchy quality to them.

\section{Images}

One of the challenges with this piece of research is that the most popular or acclaimed paintings are also the most widely reproduced and therefore the most accessible. Paintings that were perhaps considered by the artists or collectors to be of an inferior quality are not so easily accessed. The provenance of paintings can also be a significant challenge. With this in mind, all available paintings were sourced from reputable Internet sites such as online art galleries, the online art auction house Christies, The National Gallery of Ireland, and private collections (e.g., Norval Morrisseau Unlimited). Statistical analysis and empirical research favor equal- 


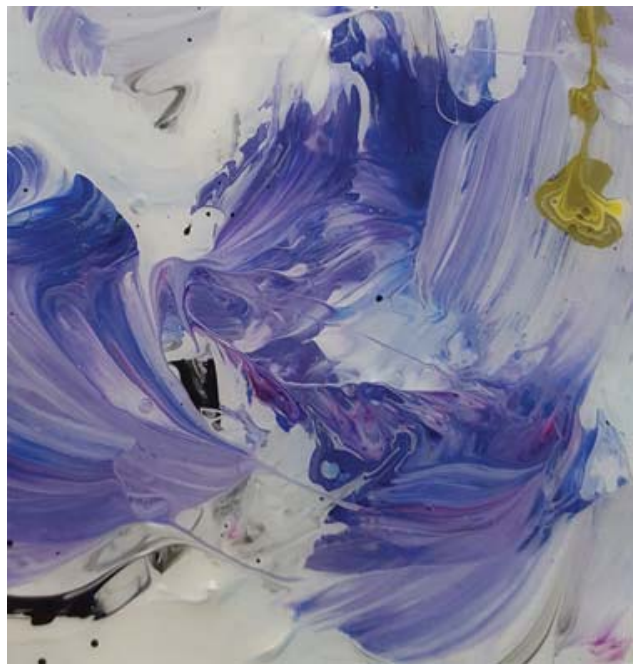

Figure 7. Danielle O'Connor Akiyama. Subsection of "Gift of Joy" (2011). Courtesy of Alex Forsythe. See the online article for the color version of this figure.

ity during the research procedure; this is to ensure the results are as fair and as reliable as possible. The infrequent number of paintings created per annum meant that exact equality would be impossible. For prolific painters such as Dalí, this was less of an issue. However, for other artists, both the sporadic availability of paintings and the fact that artists do not neatly produce an equal number of paintings per year proved more of a challenge. To overcome this challenge, linear effects mixed modeling and productivity analysis were applied in our analysis. In total, 2,092 digital images were individually analyzed. This sample represents all the available images that we were able to access: Dalí, $n=322$; Morrisseau, $n=325$; Brooks, $n=139$; De Kooning, $n=199$; Chagall, $n=298$; Monet, $n=497$; and Picasso, $n=312$.

\section{Digital Images}

Fractal analysis has been used by way of determining the fractal qualities of digital images of natural scenes (Pentland, 1984; Keller, Crownover, \& Chen, 1987), and Taylor et al. (2006) were able to analyze quality photographs of the works of Jackson Pollock. Taylor stipulated that, although the photograph could not reflect the experience of viewing a painting in a gallery, it would contain the relevant data needed for fractal analysis. His research demonstrates that a photograph of a natural scene or painting retains the information necessary for fractal analysis.

\section{Fractal Dimension}

FD is a measure of how completely a pattern fills a space. There are various methods for measuring it and all are based on a power law that generates scale-invariant properties (Taylor \& Sprott, 2008).

The formula

$$
D=\frac{\left(\frac{L 2}{L 1}\right)}{\left(\frac{S 1}{S 2}\right)}
$$

defines the dimension, $D$, as any real number between 1 and 2. $L 1$ and $L 2$ are the measured lengths of the curves (in units) and $S 1$ and
$S 2$ are the sizes of the units (i.e., the scales) used in the measurements.

The FD of the images analyzed in this study were calculated using the public domain image-processing program ImageJ (Rasband, 2013). To prepare the images for analysis they were converted to black and white using the binary threshold algorithm within ImageJ. This transformation enables an analysis of the images' fundamental geometric features. This is a manual transformation, as it requires a human observer to make a judgment regarding what part of the image is the foreground or background.

To calculate $D$, the box-counting method was used. The boxcounting dimension is widely used because it can measure images that are not self-similar and most naturally occurring curves and surfaces are not entirely self-similar. The calculation involves breaking an image into smaller box-shaped pieces (Mandelbrot, 1984; Mandelbrot \& Blumen, 1989). To do so, an image must be mapped onto a grid. The $x$-axis of the grid is $S$, where $S=1 /$ (width of the grid). For example, if the grid is 240 blocks high and 120 blocks wide, then $S=1 / 120$. The number of blocks that the image touches as well as any empty blocks are then counted $[N(S)]$. The grid is resized to a finer magnification and the process repeated. Different magnifications can then be compared. In this case the numbers of squares $(N)$ are counted as the magnification is reduced and consequentially the size of the squares $(L)$. Fractal patterns are determined by $N(L)$ through a power law relationship $N(L) \sim L^{-D}$, where $D$ lies between 1 and 2 and generates the scale invariance. The values are often plotted on a graph where the $x$-axis is $\log (S)$ and the $y$-axis is $\log [N(S)] . D$ can then be derived from the slope of the resulting curve.

To obtain a standard measure of FD using the box-counting method it was necessary, for purposes of comparability, that the same definition be applied to the whole image set. The box counts were initially set at 2, 4, 8, 16, 32, 64, 128, 256, 512, 1,024. We manually backtracked from a box count of 1,024 to 720 because beyond this level there were no statistical differences in $D$ to the fourth decimal place. The box sizes for all images were then set between 1 and 720. ImageJ binary threshold conversion was used for all images. Each image was also visually inspected to ensure that the algorithm correctly distinguished foreground from background in calculating $D$. For further reading on fractal analysis, see Brown and Liebovitch (2010) and Street et al. (2016).

\section{Statistics}

Linear mixed modeling was used to analyze the FD of the seven artists' work. This form of analysis incorporates fixed and random effect terms in one linear model (Baayen, Davidson, \& Bates, 2008) and also allows for a combination of categorical "treatment" variables and continuous covariates. For further reading on linear mixed effects modeling, see Galecki and Burzykowski (2013). Here, the dependent variable is the FD of the paintings produced by the artists in the sample. This is measured over the lifetime of the artist. The two main independent variables are age and health (i.e., whether or not the artist ultimately succumbed to a neurodegenerative disorder). The two independent, fixed (as opposed to random) variables in the model are age, which is used both as a linear and quadratic, and health, which is coded as a set of contrasts between the healthy controls and those who ended up developing either AD or PD. Note that we control for the natural 
variability between artists' styles by quantifying a painting's FD with respect to the artist's own overall average FD.

Once a mixed-effects model has been fitted to the data, the set of estimated parameters include coefficients for fixed effects in addition to the standard deviations and correlations for the random effects (Baayen et al., 2008). Mixed-effects modeling affords the opportunity to observe whether there are differences in the dependent variables as a function of specific random effects. In this case, the chosen random effect is the individual artist. Mixed-effects modeling allows us to ask the question whether specific artists showed different rates of change in their paintings' FD over time.

\section{Results}

Figure 8 compares the age variation in FD of paintings by the control group with those by artists who developed either AD or PD. The lines represent the best fit of a second-order polynomial and the gray bands represent the standard error. In the case of artists who ultimately developed $\mathrm{AD}$, a negative linear trend as a function of age can be clearly seen, whereas the slope is positive for the control group. In contrast, there is a distinct curvilinear trend apparent in the case of those artists who developed PD.

Note that age represents the age covariate centered about the mean and that age $\mathrm{a}^{2}$ is the same term squared (see Table 1). Centering makes the model estimates easier to interpret in terms of changes to FD as a function of age. There are two contrasts of central interest: control versus $\mathrm{AD}$ and control versus PD. The interactions between the covariates and contrasts are given in the last few rows of the model. For example, Age $\times$ Controlversus-AD represents the interaction of the linear age term with the control versus $\mathrm{AD}$ contrast.

The results indicate that there is a significant positive overall linear trend in FD as a function of age $(t=3.994 ; p<.001)$. Interestingly, the overall difference in FD between the control group and the two groups suffering from neurological disorders is not significant. However, the interaction between the contrasts and the linear and, to a lesser extent, the quadratic terms for age are significant, which is in line with what we would expect from the patterns apparent in Figure 9. There is a highly significant interaction between age and the Control-AD contrast $(t=-4.563 ; p<$ $.001)$. The AD artists show a decline of about 0.003 in average FD per year. In the case of the artists who developed $\mathrm{PD}$, there is also a linear decline $(t=-1.809 ; p=.07)$ and a quadratic pattern in the form of an inverted- $U$ shape $(t=-1.878 ; p=.06)$, both of which are just short of statistical significance. We also carried out a post hoc power analysis of the Age $\times$ Control-AD interaction. Using effect sizes derived from the mixed-effects model, we carried out 1,000 model fittings involving simulated data (Gelman $\&$ Hill, 2007). The significant Age $\times$ Control-AD interaction was replicated in all of the simulations. Therefore, notwithstanding the small sample of individual artists, the linear decline in FD as a function of age for the AD artists can be considered a robust effect. To give some idea of overall fit, an $R^{2}$ analogue, $\Omega^{2}$ (Xu, 2003),

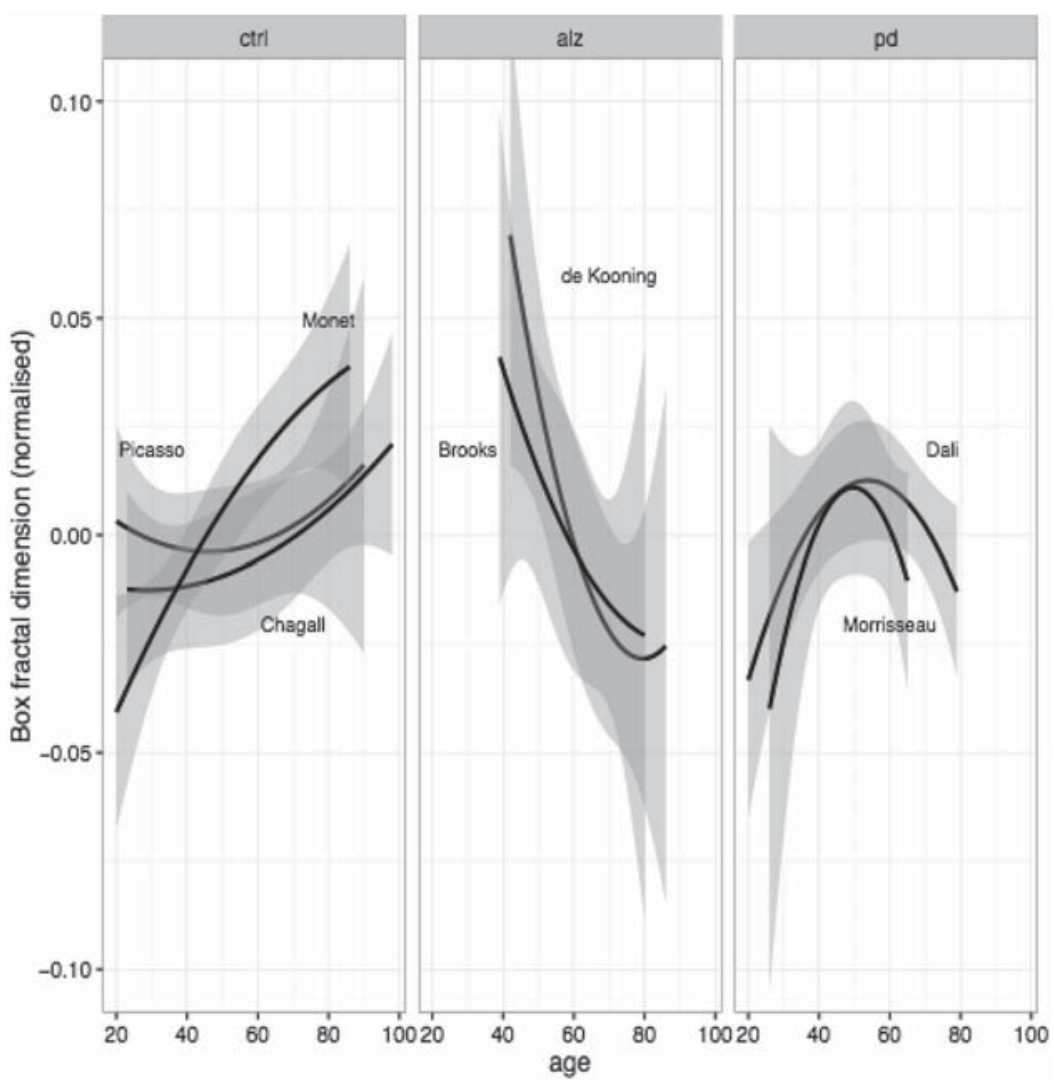

Figure 8. Fractal dimension of work as a function of artist age and neurodegenerative disorder. 
Table 1

A Linear Mixed-Effects Model to Predict Fractal Dimension as a Function of Age and Health Condition of the Artist

\begin{tabular}{lrrrc}
\hline \multicolumn{1}{c}{ Term } & \multicolumn{1}{c}{ Estimate } & \multicolumn{1}{c}{$S E$} & \multicolumn{1}{c}{$t$} & $p$ \\
\hline (Intercept) & $1.903 \mathrm{e}-03$ & $4.239 \mathrm{e}-03$ & .449 & .6534 \\
Age & $5.358 \mathrm{e}-04$ & $1.342 \mathrm{e}-04$ & 3.994 & $<.001$ \\
Age & $-1.317 \mathrm{e}-06$ & $6.869 \mathrm{e}-06$ & -.192 & .8479 \\
Control-AD & $9.296 \mathrm{e}-03$ & $7.908 \mathrm{e}-03$ & 1.175 & .2400 \\
Control-PD & $7.680 \mathrm{e}-03$ & $7.807 \mathrm{e}-03$ & .984 & .3254 \\
Age $\times$ Control-AD & $-3.045 \mathrm{E}-03$ & $6.674 \mathrm{e}-04$ & -4.563 & $<.001$ \\
Age $\times$ Control-PD & $-5.915 \mathrm{e}-04$ & $3.269 \mathrm{e}-04$ & -1.809 & .0706 \\
Age $^{2} \times$ Control-AD & $4.043 \mathrm{e}-05$ & $3.579 \mathrm{e}-05$ & 1.130 & .2588 \\
Age $^{2} \times$ Control-PD & $-3.571 \mathrm{e}-05$ & $1.901 \mathrm{e}-05$ & -1.878 & .0605 \\
\hline
\end{tabular}

Note. $\mathrm{AD}=$ Alzheimer's disease $\mathrm{PD}=$ Parkinson's disease. Significance probabilities are calculated using Satterthwaite's (1946) method for approximating degrees of freedom.

suitable for mixed-effects models was calculated for the linear model with and without the addition of a quadratic age term. This gave an $\Omega^{2}$ value of 0.021 for the model without the quadratic term, and a slightly larger 0.024 with its addition.

\section{Productivity Analysis}

The output of each artist was included as an independent measure (see Figure 9). Productivity, on its own did not improve the predictions of the FD of the artist's work, however it did interact significantly with one of the degenerative conditions $(t=2.03$, $p<.05)$. In contrast to controls, where artists with PD had periods of output above their annual average, their output was of a higher FD.

\section{Discussion}

We have analyzed 2,092 images from seven artists across their lifetime with a view to determining meaningful changes in the FD of art across the lifetime of artists who suffered from PD and AD. In contrast to the control artists reported here who did not suffer neurodegeneration, there are some overall differences between PD and AD artists. Artists with neurodegenerative conditions present more heterogeneity in the FD of their paintings. Artists who age normally, even those like Picasso who regularly varied their personal style, tended to stay within a much smaller range of FD. If we consider these results in light of findings from linguistic analysis, authors may change the style of the "story" from inner lives, to philosophy to romance, but the style of prose or syntactic structure will often be consistent with that authors "voice." In much the same way, painters will work within a different style or genre, but the FD in which they operate will remain comparable. These results are supported by previous findings by Taylor et al. (2006) in their fractal examination of the work of Jackson Pollock. Pollock operated within a specific FD, a measure so finely tuned that it has been applied as a test for fraudulent paintings.

The work of artists with AD (De Kooning and Brooks) shows a steady decline in FD from about age 40. In contrast to the controls, the art of the $\mathrm{AD}$ group presents greater variance in FD across time. PD

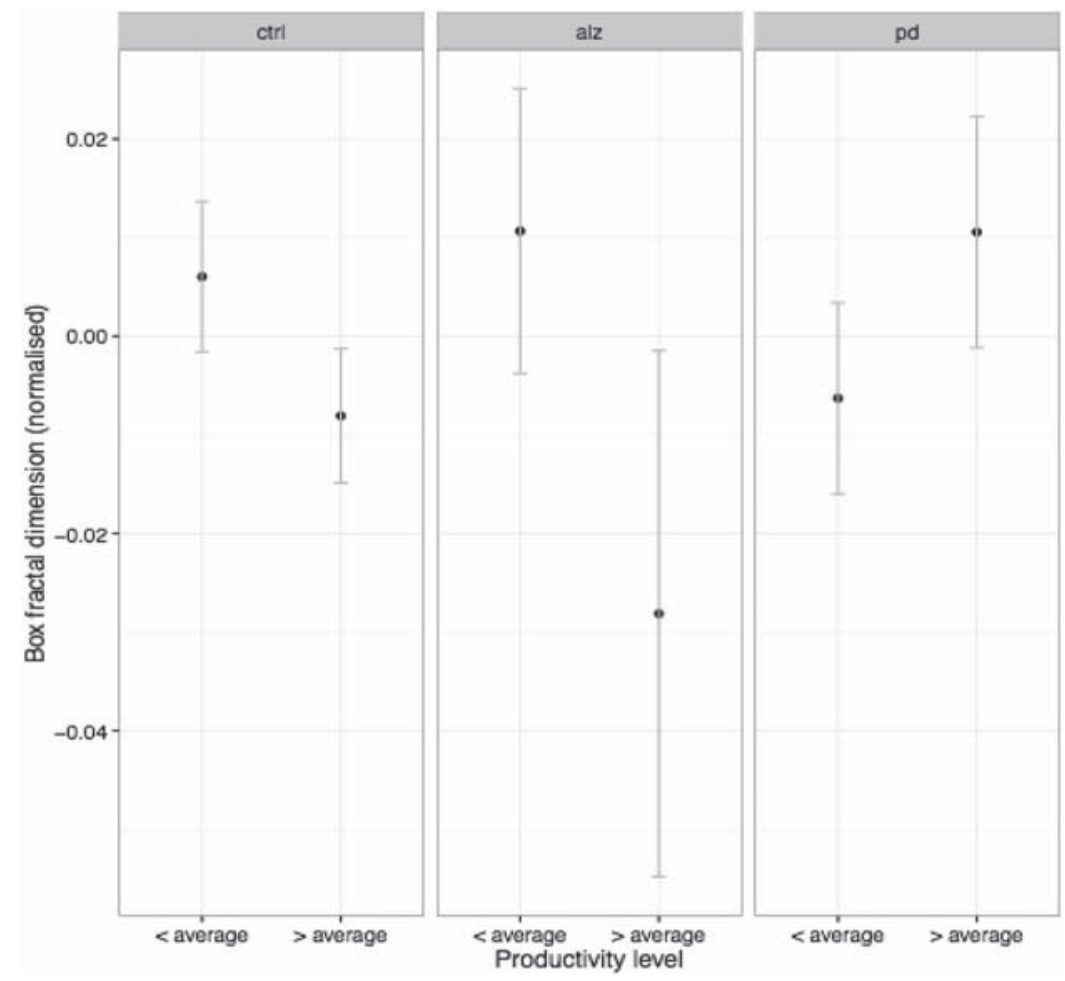

Figure 9. Fractal dimension of paintings as a function of condition and whether they were produced in a period of above or below average productivity as measured by the average yearly output of the artist. Note the reversal of the pattern for the Parkinson's disease condition. 
artists present a marginally significant inverted-U shaped pattern. Moreover, as their output increased, so did the FD of their work. This increased output of a higher FD continues until their late 50s before declining. The artists concerned, Dalí and Morrisseau, both started painting at a much lower fractal range than other artists in this sample, gradually increasing the FD of their paintings to the level of FD where the other artists in this sample commenced their career. PD is a late middle-age disorder with onset typically around 60 years of age, so it is difficult to draw the conclusion that an earlier propensity to create simpler images is a feature of PD. Both artists concerned could be broadly described as painting in a representational style, with aspects that are recognizable in some way. The increase in FD over lifetime may simply reflect increasing personal skill in managing detail within their paintings. Or it could also be a side effect of dopamine agents, which are known to provoke new behavioral responses and to increase artistic output. (Inzelberg, 2013)

This is a small sample study covering different neuropsychological conditions that can only support tentative conclusions. Identifying changes in someone's behavior that can predict clinical diagnoses years later is challenging. Often a promising method does not replicate in subsequent studies (Bissell, 2013) and the small sample size here is undoubtedly a weakness of this study. However, these findings are of importance for two reasons. Our data adds to that already gathered to determine the provenance of paintings by artists such as Jackson Pollock (Taylor et al., 2006). We build on this research by providing an increased range of fractal data for artists across their lifetime output. Researchers can now evaluate the authenticity of paintings, taking into consideration neurological damage that could place a painting outside the artist's normal FD range for a specific period in time. Second, this study demonstrates that it could be possible to identify changes in the structure of a painting, years before diagnosis of a neurological disorder. In much the way that linguists have been able to determine changes in the diaries from the Nun Study, the writings of authors and the speeches of politicians, fractal analysis can determine the changes that take place within the pattern of brush strokes of a painting.

Accessibility to the work of all of the artists in this study has been an issue. Accessible paintings tend to be well known and are often widely reproduced for public consumption, but are not necessarily representative of all works produced by the artist. Some paintings are inaccessible to researchers and the general public and are likely to remain so. We have been assisted by museum curators and have been able to secure access to some works held in private collections. Nonetheless, it should be kept in mind that the elements of an artist's oeuvre, while not random, are to some degree contingent. Creative individuals express themselves in many ways and at many different levels. Available works exist because the artist has permitted them to do so. Artists such as Vincent Van Gogh, Paul Cézanne, and Francis Bacon would radically alter, mutilate, and even destroy their paintings. Those paintings that do exist are examples that reflect not only the thematic and aesthetic concerns of the artist, but also the artist's attitude toward their creation. If the work exists then one can infer that the artist found the composition to be exceptional in some way. As such the examination of the life of an artist through the structural examination of their paintings is not a candid journal of expression across time. Something that is of course no truer for painters than it is for writers and other artists. With these caveats in mind, we offer a unique window onto the pattern of structural changes over time in the work of seven artists.

\section{References}

Baayen, R. H., Davidson, D. J., \& Bates, D. M. (2008). Mixed effects modelling with crossed random effects for subjects and items. Journal of Memory and Language, 59, 390-412. http://dx.doi.org/10.1016/j.jml 2007.12.005

Bissell, M. (2013). Reproducibility: The risks of the replication drive. Nature, 503, 333-334. http://dx.doi.org/10.1038/503333a

Bogousslavsky, J., \& Boller, F. (Eds.). (2005). Neurological disorders in famous artists: Frontiers of neurology and neuroscience Volume 19. Basel, Switzerland: Karger. http://dx.doi.org/10.1159/isbn.978-3-31801206-4

Brown, C., \& Liebovitch, L. (2010). Fractal analysis. Thousand Oaks, CA: Sage.

Chaterjee, A., Widick, P., Sternschein, R., Smith, W. B., \& Bromberger, B. (2010). The assessment of art attributes. Empirical Studies of the Arts, 28, 207-222. http://dx.doi.org/10.2190/EM.28.2.f

Chatterjee, A. (2004). Prospects for a cognitive neuroscience of visual aesthetics. Bulletin of Psychology and the Arts, 4, 55-60.

Chatterjee, A., Hamilton, R. H., \& Amorapanth, P. X. (2006). Art produced by a patient with Parkinson's disease. Behavioural Neurology, 17, 105108. http://dx.doi.org/10.1155/2006/901832

de Souza, L. C., Cerqueira, G. H., Teixeira, A. L., Caramelli, P., Levy, R., Dubois, B; Voile, E. (2014). Frontal lobe neurology and the creative mind. Frontiers in Psychology, 5, 761. http://dx.doi.org/10.3389/fpsyg 2014.00761

de Souza, L. C., Volle, E., Bertoux, M., Czernecki, V., Funkiewiez, A., Allali, G., . . . Levy, R. (2010). Poor creativity in frontotemporal dementia: A window into the neural bases of the creative mind. Neuropsychologia, 48, 3733-3742. http://dx.doi.org/10.1016/j.neuropsychologia.2010.09.010

Elkins, J. (2000). What painting is. New York, NY: Routledge.

Espinel, C. H. (1996). De Kooning's late colours and forms: Dementia, creativity, and the healing power of art. The Lancet, 347, 1096-1098. http://dx.doi.org/10.1016/S0140-6736(96)90285-8

Espinel, C. H. (2007). Memory and the creation of art: The syndrome, as in de Kooning, of "creating in the midst of dementia"-An "ArtScience" study of creation, its "brain methods" and results. In J. Bogousslavsky, M. G. Hennerici, J. Bogousslavsky, \& M. G. Hennerici (Eds.), Neurological disorders in famous artists: Pt. 2 (pp. 150-168). Basel, Switzerland: Karger. http://dx.doi.org/10.1159/000102877

Forbes-McKay, K. E., \& Venneri, A. (2005). Detecting subtle spontaneous language decline in early Alzheimer's disease with a picture description task. Neurological Sciences, 26, 4.243-254. http://dx.doi.org/10.1007/ s10072-005-0467-9

Fornazzari, L. R. (2005). Preserved painting creativity in an artist with Alzheimer's disease. European Journal of Neurology, 12, 419-424. http://dx.doi.org/10.1111/j.1468-1331.2005.01128.x

Forsythe, A., Nadal, M., Sheehy, N., Cela-Conde, C. J., \& Sawey, M. (2011). Predicting beauty: Fractal dimension and visual complexity in art. British Journal of Psychology, 102, 49-70. http://dx.doi.org/10 $.1348 / 000712610 X 498958$

Galecki, A., \& Burzykowski, T. (2013). Linear mixed effects models using R: A step-by-step approach. New York, NY: Springer. http://dx.doi.org/ 10.1007/978-1-4614-3900-4

Garrard, P., Maloney, L. M., Hodges, J. R., \& Patterson, K. (2005). The effects of very early Alzheimer's disease on the characteristics of writing by a renowned author. Brain: A Journal of Neurology, 128, 250-260. http://dx.doi.org/10.1093/brain/awh341

Garrels, G. (1997). Willem De Kooning: The late paintings, the 1980s. Minneapolis, MN: The San Francisco Museum of Modern Art and the Walker Art Center.

Gelman, A., \& Hill, J. (2007). Data analysis using regression and multilevel/hierarchical models. Cambridge, United Kingdom: Cambridge Press. 
Gordon, R., \& Forge, A. (1989). Monet. New York, NY: Penobscot Books.

Gouyet, J. F. (1996). Physics and fractal structures. New York, NY: Springer-Verlag.

Gretton, C., \& ffytche, D. H. (2014). Art and the brain: A view from dementia. International Journal of Geriatric Psychiatry, 29, 111-126. http://dx.doi.org/10.1002/gps.3975

Hagerhall, C. M., Laike, T., Taylor, R. P., Küller, M., Küller, R., \& Martin, T. P. (2008). Investigations of human EEG response to viewing fractal patterns. Perception, 37, 1488-1494. http://dx.doi.org/10.1068/p5918

Hannemann, B. T. (2006). Creativity with dementia patients. Can creativity and art stimulate dementia patients positively? Gerontology, 52, 59-65. http://dx.doi.org/10.1159/000089827

Inzelberg, R. (2013). The awakening of artistic creativity and Parkinson's disease. Behavioral Neuroscience, 127, 256-261. http://dx.doi.org/10 $.1037 / \mathrm{a} 0031052$

Keller, J. M., Crownover, R. M., \& Chen, R. Y. (1987). Characteristics of natural scenes related to the fractal dimension. IEEE Trans PAMI, 9, 621-627. http://dx.doi.org/10.1109/TPAMI.1987.4767956

Leslie, M. (2004). Novelist's final work reveals signs of Alzheimer's disease. Environment, 51, 113.

Mandelbrot, B. B. (1984). The fractal geometry of nature. San Francisco, CA: W. H. Freeman \& Co.

Mandelbrot, B. B., \& Blumen, A. (1989). Fractal geometry: What is it, and what does it do? Royal society of London: Mathematical and Physical Sciences, 423, 3-16.

Mandelbrot, B. B. (1977). The fractal geometry of nature. San Francisco, CA: W.H. Freeman and Company.

Maurer, K., \& Prvulovic, D. (2005). Carolus Horn: When the images in the brain decay: Evidence of backward-development of visual and cognitive functions in Alzheimer's disease. In J. Bogousslavsky \& F. Boller (Eds.), Neurological disorders in famous artists: Frontiers of neurology and neuroscience Volume 19 (pp. 101-111). Basel, Switzerland: Karger. http://dx.doi.org/10.1159/000085608

Mell, J. C., Howard, S. M., \& Miller, B. L. (2003). Art and the brain: The influence of frontotemporal dementia on an accomplished artist. Neurology, 60, 1707-1710. http://dx.doi.org/10.1212/01.WNL.0000064164 .02891 .12

Pentland, A. P. (1984). Fractal-based descriptions of natural scenes. IEEE Transactions on Pattern Analysis and Machine Intelligence, 6, 661-674.

Pinker, S. (2002). Art movements. Canadian Medical Association Journal, 166, 224.
Rasband, W. (2013). ImageJ. Retrieved from https://imagej.nih.gov/ij/ index.html

Sahlas, D. J. (2003). Dementia with Lewy bodies and the neurobehavioral decline of Mervyn Peake. Archives of Neurology, 60, 889-892. http:// dx.doi.org/10.1001/archneur.60.6.889

Satterthwaite, F. E. (1946). An approximate distribution of estimates of variance components. Biometrics Bull, 2, 110-114.

Snowdon, D. A., Kemper, S. J., Mortimer, J. A., Greiner, L. H., Wekstein, D. R., \& Markesbery, W. R. (1996). Linguistic ability in early life and cognitive function and Alzheimer's disease in late life. Findings from the Nun Study. Journal of the American Medical Association, 275, 528 532. http://dx.doi.org/10.1001/jama.1996.03530310034029

Street, N., Forsythe, A. M., Reilly, R., Taylor, R., \& Helmy, M. S. (2016). A complex story: Universal preference vs. individual differences shaping aesthetic response to fractals patterns. Frontiers in Human Neuroscience, 10, 213. http://dx.doi.org/10.3389/fnhum.2016.00213

Taylor, R. P., Micolich, A. P., \& Jonas, D. (1999). Fractal analysis of Pollock's drip paintings. Nature, 399, 422. http://dx.doi.org/10.1038/ 20833

Taylor, R. P., \& Sprott, J. C. (2008). Biophilic fractals and the visual journey of organic screen-savers. Nonlinear Dynamics Psychology and Life Sciences, 12, 117-129.

Taylor, R. P., Guzman, R., Martin, T. P., Hall, G. D. R., Micolich, A. P., Jonas, D., . . Marlow, C. A. (2007). Authenticating Pollock paintings using fractal geometry. Pattern Recognition Letters, 28, 695-702.

Van Buren, B., Bromberger, B., Potts, D., Miller, B., \& Chatterjee, A. (2013). Changes in painting styles of two artists with Alzheimer's disease. Psychology of Aesthetics, Creativity, and the Arts, 7, 89-94. http://dx.doi.org/10.1037/a0029332

Walker, R. H., Warwick, R., \& Cercy, S. P. (2006). Augmentation of artistic productivity in Parkinson's disease. Movement Disorders, 21, 285-286. http://dx.doi.org/10.1002/mds.20758

$\mathrm{Xu}$, R. (2003). Measuring explained variation in linear mixed effects models. Statistics in Medicine, 22, 3527-3541. http://dx.doi.org/10 $.1002 / \operatorname{sim} .1572$

Received September 22, 2013

Revision received June 12, 2016 Accepted June 15, 2016 